cin, penicillin, and kanamycin was tested. Assays of serum specimens before and after treatment, and of stool specimens taken at various time intervals after oral administration of the antibiotics, showed that absorption of these antibiotics was normal.

\section{DISCUSSION}

Approximately 35 different species of microorganisms have been isolated from the patient at various times, taking into account that the same organisms may occasionally have been identified under different names in different laboratories. Colonization by about 10 of these has occurred at some time during his life. It is highly important, therefore, to note that $D V$ has handled these microorganisms without difficulty, has had no evidence of infection and has, since birth, always been in excellent health. Although there is no indication that he has been colonized by frankly pathogenic organisms, a number of organisms which could be pathogenic under some circumstances have been isolated. These include $A$. faecalis (eradicated by antibiot-

Copyright 11977 International Pediatric Research Foundation, Inc. ics), both Candida species (part of the autoflora), Aspergillus (isolated on two occasions), B. clostridiiformis ss. clostridiiformis (part of the current autoflora) and $S$. epidermidis (part of the autoflora since the third month).

Although at least six organisms are currently present in his autoflora, he cannot be said to have a normal microflora. Quantitatively, anaerobic bacteria are below levels seen in normal subjects. For example, the fecal concentration rarely surpassed $10^{8}$ organisms/g vs. $10^{10}-10^{11} / \mathrm{g}$ for normal humans $(15,38)$. Qualitatively, his flora has abnormally few species and lacks most of those commonly isolated in studies of the flora of normal subjects in which as many as $\mathbf{2 5}$ species of anaerobes alone may be identified in the colon (37). Missing are the frequently occurring species of Enterobacteriaceae (with the exception of $E$. agglomerans), Streptococcus, Lactobacillus, Veillonella, Bifidobacterium, and Eubacterium (53).

Although the microbial autoflora in the early part of $D V$ 's life has been significantly simpler than that of nonisolated children, this difference has not interfered with his normal development in any way that is apparent at the present time.

Pediat. Res. 11: 71-78 (1977)

\title{
IV. Immunologic Studies
}

\author{
MARY ANN SOUTH, JOHN R. MONTGOMERY, ELLEN RICHIE, NALINI MUKHOPADHYAY, B. \\ SUE CRISWELL, BRUCE F. MACKLER, SALLY R. DE FAZIO, PATRICIA BEALMEAR, LYLE R. \\ HEIM, JOHN J. TRENTIN, GORDON R. DRESSMAN, AND PEGGY O'NEILL \\ Departments of Pediatrics, Microbiology and Immunology, Virology, and Division of Experimental Biology, Baylor \\ College of Medicine and Research Hematology Laboratory, Texas Children's Hospital and Johnson Space Center, \\ National Aeronautics and Space Administration, and Dental Science Institute, University of Texas Dental Branch, \\ University of Texas Health Science Center, Houston, Texas, USA
}

The four-year survival of this SCID patient under gnotobiotic conditions has provided unprecedented opportunity for serial studies of the immune defect in a subject who is free of debilitating illness that could affect the immunologic status.

\section{METHODS AND MATERIALS}

The technique for applying skin windows to study leukocyte function was adapted from the method of Rebuck and Crowley (44) as follows: the skin site, usually the volar surface of the arm, was cleansed. The skin was held taut and a no. 15 scalpel blade was used to scrape away the epithelium from 3-4-mm area through the papillary layer of the corium until bleeding points appeared. A drop of sterile bovine albumin $(30 \%)$ was placed on the scraped area and covered with a sterile coverslip and cardboard. A cork disk was placed on top to maintain pressure. The skin on either side of the scraped and covered area was painted with tincture of benzoin and the covers secured with a strip of 2-inch Elasticon. The coverslips, changed every $2 \mathrm{hr}$ for $24 \mathrm{hr}$, were stained with Wright-Giemsa solution.

Thymosin assays to 8.5 months of age (61) were done by the method of Bach et al. (4). Thymosin studies at 2.5 years were done as follows: mononuclear cells from the patient and an age- matched control subject were incubated with varying concentrations of thymosin (65) at $37^{\circ}$ for $60 \mathrm{~min}$; after incubation the cells were placed in culture with varying concentrations of PHA, HA-17 purified from Burroughs Wellcome, and cultured for 72 hr at $37^{\circ}$ in $5 \% \mathrm{CO}_{2}$ in an air atmosphere $(30) ; 18 \mathrm{hr}$ before harvesting, $20 \mu \mathrm{l}$ of $5 \mathrm{Ci} / \mathrm{ml}\left[{ }^{3} \mathrm{H}\right]$ thymidine was added; harvesting was done utilizing a Mash II automatic harvester (66).

In serum complement studies (60) the C1q, C3, C4, and C5 were measured by radial immunodiffusion. Serum immunoglobulin levels were done by radial diffusion techniques using commercial agar plates. Behring Partigen plates, able to detect levels as low $3 \mathrm{mg} / 100 \mathrm{ml}$, were used until the patient was 13 months old; after that Meloy low level immunodiffusion plates, capable of detecting levels of $8 \mathrm{mg} / 100 \mathrm{ml}$ for $\mathrm{IgG}$ and $9 \mathrm{mg} / 100 \mathrm{ml}$ for IgM, were used. Using Meloy low level IgA plates and a known standard, the lowest level detectable was found to be $1 \mathrm{mg} / 100$ $\mathrm{ml}(67)$.

The ability of the patient's lymphocytes to respond to mitogens was tested in one-way MLC and in lymphocyte cultures to which PHA, PWM, or other mitogenic agents were added. PHA (M form) from BACTO or GIBCO was used except that, in the purified $T$ cell studies, Burroughs Wellcome purified PHA HA17 was used. These tests were done using isolated leukocyte and 
whole blood techniques which have been previously described $(3,36,42,48)$. Purified T cells, prepared by sheep erythrocyterosetting techniques, were assayed for blastogenesis by a microtechnique previously described $(29,30)$.

Transfer factor was prepared from leukocytes obtained from an adult human donor using the IBM cell separator as described elsewhere (13). The patient received four intramuscular injections of TF, $0.15 \mathrm{U}$ on August 10,1972, $0.25 \mathrm{U}$ on August 28, $1972,0.4 U$ on September 11, 1972, and $0.25 U$ on January 19, 1973, a unit being the amount of TF obtained from approximately $5 \times 10^{8}$ leukocytes. The patient's response to specific antigens (to which the TF donor was sensitive) were evaluated in vivo by skin tests and in vitro by lymphocyte culture techniques.

Cytotoxicity and lymphokine responses induced via complement (C3) membrane receptors were investigated by the method of O'Neill et al. (41). Lymphoid subpopulations from the patient and also from normal adult donors were separated by sequential erythrocyte rosetting as follows: $T$ cells forming rosettes with fresh sheep erythrocytes were first separated from non-E-rosetting cells (29). Then the non-E-rosetting cells were activated by incubation with erythrocytes coated with $19 \mathrm{~s}$ anti-erythrocyte globulin and fresh mouse complement (EAC) to form EAC rosettes, a B-cell characteristic (25). Material to be tested for lymphokines (lymphotoxin and migration inhibition factor) was obtained by harvesting the supernates from $24-\mathrm{hr}$ cultures of these lymphocyte subpopulations $\left(5 \times 10^{8}\right.$ cells/culture $)$. The cytotoxic activities and lymphotoxin production of lymphoid subpopulations were quantitated using chromate $\left({ }^{31} \mathrm{Cr}\right)$-labeled human melanoma (SH-1) and lung fibroblast (WI-38) target cells. Human leukocyte migration inhibition assays were performed by the micromethod of Federlin et al. (17).

Except as specified in the text all other tests were done by standard techniques currently used in clinical laboratory diagnosis.

\section{RESULTS}

\section{TESTS OF PHAGOCYTIC FUNCTION}

Phagocytic functions appeared normal as indicated by the following tests. A Nitroblue tetrazolium test for neutrophile function, done at 3 weeks of age, was normal. When the patient was 1 month old, killing of Staphylococcus by his phagocytes showed a normal curve in comparison to the control. Rebuck skin windows at 2 months, 10 months, and 16 months of age showed normal responses of the neutrophiles after simple abrasion. The mononuclear phase was hypocellular, those cells seen being abnormal and unidentifiable.

\section{SERUM COMPLEMENT ASSAY}

At 20 months the serum complement levels (Table 1) were considered to be within normal limits except the Clq which was low at $30 \%$ of the normal serum pool value.

\section{RESPONSE TO SKIN GRAFT}

When $D V$ was 6 months old a skin graft from an unrelated donor was placed on the proximal surface of the upper left arm along with an autochthonous graft. There was good healing and no evidence of rejection of either graft and they both remain in place to the present time.

Table 1. Serum complement levels at 20 months of age

\begin{tabular}{lccrr}
\hline & \multicolumn{4}{c}{ Complement fraction, $\mu \mathrm{g} / \mathrm{ml}$} \\
\cline { 2 - 5 } & $\mathrm{C3}$ & $\mathrm{C} 4$ & $\mathrm{C5}$ & $\mathrm{C1q}$ \\
\hline SCID $^{1}$ patient & 1,467 & 845 & 61 & 48 \\
Normal serum pool & 1,847 & 945 & 101 & 160 \\
\hline
\end{tabular}

' Severe combined immune deficiency.
Table 2. Effect of thymosin on phytohemagglutinin (PHA) stimulation of mononuclear cells from severe combined immune deficiency (SCID) patient and normal donor at 30 months

\begin{tabular}{cccccr}
\hline $\begin{array}{c}\text { Thymo- } \\
\text { sin, } \mu \mathrm{g} / \\
\text { well }\end{array}$ & $\begin{array}{c}\text { PHA, } \\
\mu \mathrm{g} / \text { well }\end{array}$ & $\begin{array}{c}\text { SCID pa- } \\
\text { tient, cpm } \\
\text { SE }^{2}\end{array}$ & SI $^{3}$ & $\begin{array}{c}\text { Normal control, } \\
\text { cpm } \pm \text { SE }\end{array}$ & \multicolumn{1}{c}{ SI } \\
\hline 0 & 0 & $92 \pm 3$ & 1.0 & $100 \pm 14$ & 1.0 \\
& 0.5 & $97 \pm 5$ & 1.1 & $3,322 \pm 131$ & 33.2 \\
& 1.0 & $93 \pm 2$ & 1.0 & $1,788 \pm 98$ & 17.9 \\
& 2.5 & $60 \pm 6$ & 0.7 & $277 \pm 29$ & 2.8 \\
100 & 0 & $84 \pm 4$ & 1.0 & $99 \pm 21$ & 1.0 \\
& 0.5 & $69 \pm 10$ & 0.8 & $1,974 \pm 291$ & 19.7 \\
& 1.0 & $85 \pm 8$ & 1.0 & $2,238 \pm 178$ & 22.4 \\
& 2.5 & $85 \pm 3$ & 1.0 & $75 \pm 11$ & 0.8 \\
200 & 0 & $123 \pm 16$ & 1.0 & $98 \pm 9$ & 1.0 \\
& 0.5 & $114 \pm 12$ & 0.9 & $3,580 \pm 341$ & 36.0 \\
& 1.0 & $83 \pm 9$ & 0.7 & $2,284 \pm 105$ & 23.0 \\
& 2.5 & $99 \pm 3$ & 0.8 & $102 \pm 16$ & 1.1 \\
300 & 0 & $93 \pm 7$ & 1.0 & $69 \pm 29$ & 1.0 \\
& 0.5 & $98 \pm 4$ & 1.1 & $3,787 \pm 213$ & 54.9 \\
& 1.0 & $108 \pm 5$ & 1.2 & $2,071 \pm 46$ & 30.0 \\
& 2.5 & $86 \pm 8$ & 0.9 & $89 \pm 5$ & 1.3 \\
600 & 0 & $144 \pm 11$ & 1.0 & $90 \pm 10$ & 1.0 \\
& 0.5 & $109 \pm 7$ & 0.8 & $3,300 \pm 347$ & 36.7 \\
& 1.0 & $88 \pm 3$ & 0.6 & $4,610 \pm 396$ & 51.2 \\
& 2.5 & $80 \pm 3$ & 0.6 & $235 \pm 42$ & 2.6 \\
\hline
\end{tabular}

${ }^{1}$ Reference 65.

2 Mean counts per min of triplicate cultures $\pm S E$.

${ }^{3}$ Stimulation index (stimulated/unstimulated).

\section{ADA}

The patient was shown to have normal levels of the enzyme in the erythrocytes, leukocytes, and serum (62). This was the first child with SCID in the ADA study (35) who had normal ADA levels and this finding suggested that ADA deficiency is not associated with $\mathrm{X}$-linked but rather with the autosomal recessive type of SCID.

\section{THYMOSIN STUDIES}

Thymosin assays of serum obtained at birth, 5.5 months and 8.5 months of age showed values as follows: adult control subject $1 / 4,10$-year-old control subject $1 / 128$, this patient 0 . Such a lack of serum thymosin is compatible with the absence of normally functioning thymus tissue. Later, at age 2.5 years studies were made of the effect of thymosin on PHA stimulation on mononuclear cells from the patient and an age-matched control subject. The results (Table 2) suggested that some potentiation of the PHA responsiveness of the mononuclear cells may have occurred with high concentrations of thymosin $(300-600 \mu \mathrm{g} /$ $\mathrm{ml})$. However, the changes were possibly related to reduction in unstimulated activity.

\section{IMMUNOGLOBULINS}

The patient's serum immunoglobulin levels for IgM, IgG, and IgA to age 46 months are shown in Table 3 . These values were determined in the lower range of sensitivity of the agar plates. The rings found were close to the well and values obtained therefore represent estimates rather than definite values. The findings showed that the IgM levels were generally low in comparison with those of normal children of similar age; $\operatorname{lgG}$ was not detected (initial levels represented maternal IgG); no serum IgA was detected through the age of 28 months. In the early months of life a search for secretory IgA in stool extracts was made but there was no indication that any was present. Serum determinations done at 39-46 months, however, indicated very low levels of $\lg \mathrm{A}$.

Quantitative and qualitative characterization of the serum 
immunoglobulins by radial immunodiffusion, electroimmunodiffusion, immunoelectrophoresis, and chromatography have been reported previously (14) for the ages between 2 months and 25 months. These studies showed that the total immunoglobulin level was severely decreased. The levels of $\operatorname{IgM}, \mathrm{IgG}$, and $\mathrm{IgA}$ were similar to those shown in Table 3 for similar age periods. However, the IgM detected by immunoelectrophoresis at 2 months showed an abnormally fast electrophoretic mobility. Further analysis showed other abnormalities of this fraction;i.e., it was of relatively small (4s) molecular size, and contained $\mu$ heavy chain determinants but no detectable light chains. This paraprotein was still present at 25 months. In addition to $\mu$-paraprotein, three other "immunoglobulin" fractions were seen in electrophoretic studies. One showed abnormally fast mobility; the other two were within normal range. None of these reacted to monospecific antisera for $\operatorname{IgG}, \operatorname{IgA}$, or $\operatorname{IgM}$. The presence of the small paraprotein reacting with $\mu$-chain specific antibody indicates that in these early studies, the amount of $\operatorname{IgM}$ as measured by the radial diffusion technique, using the $19 \mathrm{~s}$ standard, was falsely high.

Specific $\mu$-chain paraprotein, as found in $D V$ 's serum, has also been found in several other children with SCID (both X-linked and autosomal recessive), suggesting that the finding might be of value in diagnosis of severe combined immune deficiency disease (14).

Analysis by ultracentrifugation of serum collected at about 24 months of age revealed no $19 \mathrm{~s}$ material but at 36 months both $7 \mathrm{~s}$ and $19 \mathrm{~s}$ materials were present. At 44 months these fractions were still present and the $4 \mathrm{~s}$ component had disappeared. Furthermore, radial immunodiffusion assay of plasma taken at 44 months indicated the presence of IgD. At this time, from the same sample, an IgM component of normal electrophoretic mobility was detected.

\section{ANTIBODY RESPONSES AND SKIN TESTS TO SPECIFIC ANTIGENS}

The patient received an injection of $100 \mu \mathrm{g}$ keyhole limpet hemocyanin at 1 month of age. Before injection, the serum antibody titer to KLH was 0-0 (the first number represents total antibody titer $\left(\log _{2}\right)$ and the second number the titer after mercaptoethanol digestion) (68). A skin test to KLH at 7 days postinjection was negative. The skin test dose is the same as the normal immunization dose $(100 \mu \mathrm{g})$, given intradermally, and in a normal person constitutes a reimmunization or booster injection. Serum antibody titers tested $7,10,21$, and 56 days after the first injection were $1-0,3-0,1-0$, and $1-0$, respectively, all

Table 3. Serum immunoglobulins (Ig)

\begin{tabular}{cccc}
\hline & \multicolumn{3}{c}{ Immunoglobulins, $\mathrm{mg} / 100 \mathrm{ml}$} \\
\cline { 2 - 4 } Age & IgM & IgG & IgA \\
\hline Birth & 16 & 560 & 0 \\
$1 \mathrm{wk}$ & 22 & 560 & 0 \\
$3 \mathrm{wk}$ & 30 & $\mathrm{ND}^{1}$ & $\mathrm{ND}$ \\
$7 \mathrm{wk}$ & 10 & 305 & 0 \\
$3 \mathrm{mo}$ & 32 & 130 & 0 \\
$4 \mathrm{mo}$ & 29 & 135 & 0 \\
$5 \mathrm{mo}$ & 13 & 130 & 0 \\
$6 \mathrm{mo}$ & 22 & 120 & 0 \\
$7 \mathrm{mo}$ & 17 & 105 & 0 \\
$10 \mathrm{mo}$ & 11 & 37 & 0 \\
$11 \mathrm{mo}$ & 8 & 27 & 0 \\
$12 \mathrm{mo}$ & 11 & 28 & $\mathrm{ND}$ \\
$13 \mathrm{mo}$ & 7 & 0 & 0 \\
$28 \mathrm{mo}$ & 6 & 0 & 0 \\
$39 \mathrm{mo}$ & 15 & 0 & 1.2 \\
$42 \mathrm{mo}$ & 17 & 0 & 3.7 \\
$43 \mathrm{mo}$ & 12 & 0 & 6.7 \\
$46 \mathrm{mo}$ & 10 & 0 & $<.8$ \\
\hline
\end{tabular}

' Not done.
Table 4. Mitogenic response of patient's lymphocytes in tests using isolated leukocyte technique (birth to 28 months) ${ }^{\prime}$

\begin{tabular}{|c|c|c|c|}
\hline \multirow{2}{*}{$\begin{array}{l}\text { Age, months } \\
\text { (+ days) }\end{array}$} & \multicolumn{3}{|c|}{ Stimulation index: ${ }^{2}$ patient (control) } \\
\hline & MLC & PHA & PWM \\
\hline (Birth) & & $<1.0(8.0)$ & $1.5(12.0)$ \\
\hline $0(1)$ & & $0.6(8.6)$ & $1.5(1.5)$ \\
\hline 1 & & $1.0(5.0)$ & $1.3(15.0)$ \\
\hline $2(22)$ & $\begin{array}{c}<1.0(25.9) \\
(5.9)\end{array}$ & & \\
\hline $3(16)$ & $<1.0(10.0)$ & & \\
\hline $4(5)$ & & $1.4(30.0)$ & $1.3(9.0)$ \\
\hline $5(3)$ & & $1.2(5.0)$ & $0.9(3.5)$ \\
\hline $5(20)$ & $\begin{array}{l}1.5(15.8) \\
1.2(18.5)\end{array}$ & & \\
\hline $6(30)$ & & & $<1.0(83.0)$ \\
\hline $11(23)$ & & $<1.0(453.0)$ & $1.0(77.0)$ \\
\hline $13(20)$ & & $0.7(483.0)$ & $1.1(188.0)$ \\
\hline $15(20)$ & & $0.9(127.0)$ & \\
\hline $15(23)$ & & $0.9(101.0)$ & \\
\hline $16(12)$ & $\begin{array}{l}2.6(31.0) \\
2.4(22.7)\end{array}$ & $0.6(130.0)$ & $0.4(114.0)$ \\
\hline $18(8)$ & & $0.8(250.0)$ & $1.2(122.0)$ \\
\hline $18(23)$ & $1.8(11.0)$ & $0.7(24.0)$ & $1.0(27.0)$ \\
\hline $27(26)$ & & $0.7(15.0)$ & $2.0(15.0)$ \\
\hline
\end{tabular}

' MLC: mixed lymphocyte culture; PHA: phytohemagglutin; PWM: pokeweed mitogen.

2 The stimulation index is ratio of counts per min in stimulated lymphocytes to counts per min in unstimulated lymphocytes in radioactive assay. Values for control subject are within parentheses.

insignificant levels of antibody. At 4 months $D V$ was again injected with KLH antigen; serum antibody titers at 7,10, and 24 days after injection were negative. After a further antigen injection at 8 months of age, serum antibody titers and skin tests were again all negative until at 11 months of age, on the fifth rechallenge, $D V$ had an erythematous reaction of approximately $5 \mathrm{~mm}$ diameter with no detectable induration. This was before administration of transfer factor. The day after the first dose of transfer factor the KLH skin test again showed the erythematous reaction but on subsequent tests the reactions were less pronounced; antibody responses remained insignificant. A skin test at 42 months was negative.

When the patient was 1.5 months old an injection of typhoid antigen was given intradermally in six places on the arms and thighs. (A temperature of $101.4^{\circ} \mathrm{F}$ was recorded for that day.) The febrile agglutinins tested 7 and 9 days later were negative, showing titers of $<1: 20$. Typhoid antigen, reinjected 17 days after the first injection, elicited no antibody response when tested 11 days later, and the febrile agglutinins to typhoid were $<1: 20$ at 2 and 3 months after the second injection.

Isohemagglutinin titers, both anti-A and anti-B, were negative when the patient was tested at 3 weeks, at 1 month, and at 40 months of age (blood type was $\mathrm{ABO}$ group $\mathrm{A}$ ).

\section{TEST OF IN VITRO LYMPHOCYTE RESPONSE TO MITOGENS}

In tests using the isolated leukocyte technique (Table 4) the patient's lymphocytes showed very minimal or no blastogenesis in response to PHA, PWM, or in MLC. In tests using the whole blood culture technique (Table 5), transient, low responses to PHA were observed but were not consistently maintained. Although transfer factor had been administered to the patient at 11 months of age, no increases in lymphocyte responsiveness to nonspecific mitogens occurred which could be attributed to the treatment. In general, the responsiveness of the patient's lymphocytes in MLC and in culture with various mitogenic agents was very minimal in comparison to control subjects during the first 2 years of life. 
When the patient was approximately 3 years old, $\mathrm{T}$ cells purified by erythrocyte rosette formation were incubated with PHA and assayed for blastogenic responses. Table 6 shows the results from four consecutive experiments over a 3-month period. The first experiment showed appreciable blastogenesis which was not obtained in the subsequent three experiments. The dose-response pattern and standard errors of the first experiment suggest that these results represent an actual positive response of a transient cell population.

\section{ADMINISTRATION OF TRANSFER FACTOR}

Transfer factor was given to this patient to determine whether his lymphocytes had the capacity to develop immunologic reactivity under the influence of TF. When he was between 10.5 and 11.5 months old he received three intramuscular injections of TF and at 16 months he received a fourth injection, making a total of approximately $1 \mathrm{U}$ TF.

Skin tests to antigens to which the donor was sensitive were not administered to the patient before TF injection.

Skin tests to $C$. albicans, PPD, and SK-SD were administered on several occasions after injection of TF. Although the donor possessed skin reactivity to the three antigens, none was positive in the patient, although in skin tests administered within a day after each TF injection, small areas of definite redness appeared early $(12 \mathrm{hr}$ ) and faded rapidly (by $24 \mathrm{hr}$ ). This evolution of the skin test is indicative of a very weak transfer of sensitivity. When skin tests were administered approximately a week after TF injection, there was no observable reaction.

Before administration of TF, the patient's lymphocytes did not respond significantly in vitro to C. albicans or PPD (959 and 121 $\mathrm{cpm}$, respectively, with background count of $445 \mathrm{cpm}$ ); however, they did respond with a SI of 8 in each case when TF was added to the cultures $(1,000 \mathrm{cpm}$ for each with background of $121 \mathrm{cpm})$. Two weeks after the first TF injection and after the application of the skin tests, the in vitro responses in the presence of TF were no longer obtained. After a second dose of TF and further skin test applications, however, a positive in vitro response with added TF was obtained to $C$. albicans with a SI of $14(3,236 \mathrm{cpm}$ with background of $226 \mathrm{cpm})$ but not to PPD $(271 \mathrm{cpm})$. At this time, response to the third antigen, SK-SD, was studied. Before a skin test to SK-SD had been applied, the in vitro response to SK-SD was positive both with TF added (SI 13 with $3,140 \mathrm{cpm}$, background $226 \mathrm{cpm}$ ) and without TF added (SI 8 with $3,130 \mathrm{cpm}$, background $379 \mathrm{cpm}$ ). After the first skin test to SK-SD had been applied, positive in vitro responses were no longer obtained even on repeated testing over a period of a month.

A mumps skin test applied 9 days before the fourth TF injection was negative. (The TF donor was positive to mumps antigen.) Another mumps skin test, applied 3 days after TF injection gave a very small erythematous reaction $(1.5 \mathrm{~mm})$. The in vitro responses to this antigen, before and after skin testing, were negligible.

Thus it appeared that the patient had some cells that could be influenced by TF. Although the weak in vivo responses and transient in vitro reactions were not what would be expected in a normal person, there was definite indication that some reaction took place after administration of TF, both in proliferative (in vitro) and skin test responses.

Table 5. Mitogenic response of patient's lymphocytes in tests using whole blood technique (birth to 24 months)!

\begin{tabular}{|c|c|c|c|c|c|c|}
\hline \multirow{2}{*}{$\begin{array}{l}\text { Age, months } \\
\text { (+ days) }\end{array}$} & \multicolumn{6}{|c|}{ Stimulation index: ${ }^{2}$ patient (control) } \\
\hline & PHA & PWM & Con-A & St-0 & St-0 + PHA & Lipo-B \\
\hline $0(7)$ & $1.0(24.0)$ & $0.9(8.0)$ & & & & \\
\hline $1(21)$ & $1.3(13.0)$ & & & & & \\
\hline $3(16)$ & $1.0(13.0)$ & $1.0(7.0)$ & & & & \\
\hline $7(13)$ & $4.5(7.1)$ & $1.2(2.1)$ & $2.1(0.8)$ & & & \\
\hline $7(20)$ & $1.0(11.5)$ & $1.0(5.4)$ & $0.7(23.2)$ & & & \\
\hline $7(25)$ & $0.8(2.1)$ & & & & & \\
\hline $8(2)$ & $1.1(4.2)$ & & $1.6(3.6)$ & & & \\
\hline $8(9)$ & $1.0(9.2)$ & $1.1(3.0)$ & $1.3(6.0)$ & & & \\
\hline $8(16)$ & $1.3(3.7)$ & $1.2(1.2)$ & $1.0(1.9)$ & $1.6(1.0)$ & & $1.5(1.0)$ \\
\hline $8(19)$ & & $1.0(20.0)$ & $1.2(18.0)$ & $1.8(16.0)$ & & $1.8(16.0)$ \\
\hline $9(9)$ & $3.3(19.0)$ & & & $0.9(2.4)$ & $5.1(14.4)$ & $1.3(1.0)$ \\
\hline $9(21)$ & $1.8(32.4)$ & $1.0(7.0)$ & & $1.0(4.3)$ & $1.2(33.1)$ & \\
\hline $9(30)$ & $0.9(16.4)$ & $1.1(4.4)$ & $1.0(5.2)$ & $1.0(2.7)$ & $0.9(10.2)$ & \\
\hline 10 (19) & $1.4(11.9)$ & $0.7(10.9)$ & & & & \\
\hline $11(4)$ & $1.9(12.1)$ & 1.0 & & & & \\
\hline $12(18)$ & $3.2(13.8)$ & $0.7(10.1)$ & & & & \\
\hline $12(29)$ & $0.5(7.4)$ & & & & & \\
\hline $13(11)$ & $1.1(13.5)$ & & & & & \\
\hline $13(20)$ & $1.6(20.4)$ & & & & & \\
\hline $15(20)$ & $2.0(4.8)$ & $0.7(3.2)$ & $0.8(2.4)$ & & & \\
\hline $15(27)$ & $1.2(4.3)$ & & & & & \\
\hline $16(1)$ & $9.7(25.0)$ & $0.6(17.7)$ & & & & \\
\hline $16(23$ & 2.7 (ND) & & & & & \\
\hline $17(12)$ & $3.0(\mathrm{ND})$ & & & & & \\
\hline $18(22)$ & $3.5(6.4)$ & 1.4 (ND) & & & & \\
\hline $19(11)$ & $4.1(14.6)$ & & & & & \\
\hline $22(3)$ & $0.7(3.4)$ & $0.9(5.6)$ & & & & \\
\hline $22(23)$ & $1.6(9.0)$ & & & & & \\
\hline $23(3)$ & $2.4(10.6)$ & & & & & \\
\hline $24(6)$ & $6.4(14.2)$ & & & & & \\
\hline $24(10)$ & $4.2(16.2)$ & $0.5(5.4)$ & & & & \\
\hline
\end{tabular}

' PHA: phytohemagglutin; PWM: pokeweed mitogen; Con-A: concanavalin-A; St-0: streptolysin 0; Lipo-B: lipopolysaccharide B; ND: not done.

2 Stimulation index is ratio of counts per min in stimulated lymphocytes to counts per min in unstimulated lymphocytes in radioactive assay. Values for control subject are within parentheses. 
Table 6. Phytohemagglutinin (PHA)-induced blastogenesis of purified $T$ cells from patient'

\begin{tabular}{|c|c|c|c|}
\hline $\begin{array}{l}\text { Age, months } \\
\text { (+ days) }\end{array}$ & Mitogen & $\begin{array}{c}\text { Mean } \\
\text { cpm } \pm S E\end{array}$ & SI \\
\hline \multirow[t]{4}{*}{$35(13)$} & Media control & $54 \pm 7$ & 1.0 \\
\hline & PHA $2.5 \mu \mathrm{g} /$ well & $468 \pm 33$ & 8.7 \\
\hline & PHA $2.0 \mu \mathrm{g} /$ well & $940 \pm 112$ & 17.4 \\
\hline & PHA $1.0 \mu \mathrm{g} /$ well & $421 \pm 21$ & 7.8 \\
\hline & PHA $0.5 \mu \mathrm{g} /$ well & ND & \\
\hline & PHA $0.25 \mu \mathrm{g} /$ well & $104 \pm 22$ & 1.9 \\
\hline \multirow[t]{4}{*}{$36(13)$} & Media control & $45 \pm 4$ & 1.0 \\
\hline & PHA $2.0 \mu \mathrm{g} /$ well & $91 \pm 8$ & 2.0 \\
\hline & PHA $1.0 \mu \mathrm{g} /$ well & $112 \pm 14$ & 2.4 \\
\hline & PHA $0.5 \mu \mathrm{g} /$ well & $156 \pm 11$ & 3.5 \\
\hline \multirow[t]{5}{*}{$37(26)$} & Media control & $134 \pm 5$ & 1.0 \\
\hline & PHA $2.5 \mu \mathrm{g} /$ well & $487 \pm 32$ & 3.6 \\
\hline & PHA $1.0 \mu \mathrm{g} /$ well & $418 \pm 31$ & 3.1 \\
\hline & PHA $0.5 \mu \mathrm{g} /$ well & $332 \pm 64$ & 2.5 \\
\hline & PHA $0.25 \mu \mathrm{g} /$ well & $343 \pm 39$ & 2.6 \\
\hline \multirow[t]{4}{*}{$37(8)$} & Media control & $92 \pm 4$ & 1.0 \\
\hline & PHA $2.5 \mu \mathrm{g} /$ well & $60 \pm 10$ & 0.7 \\
\hline & PHA $1.0 \mu \mathrm{g} /$ well & $97 \pm 8$ & 1.0 \\
\hline & PHA $0.5 \mu \mathrm{g} /$ well & $97 \pm 3$ & 1.0 \\
\hline
\end{tabular}

1 SI: stimulation index (ratio of counts per $\mathrm{min}$ in stimulated lymphocytes to counts per min in unstimulated lymphocytes in radioactive assay); PHA: phytohemagglutinin ND: not done; cells per culture = $2.5 \times 10^{5}$.

\section{STUDIES OF T- AND B-CELL, MARKERS}

From the studies described above it is apparent that the immune defect is associated with lymphocyte malfunctions of both the B-cell and T-cell lines. In order to obtain more specific information regarding the fundamental aspects of the immune deficiency, more detailed studies of the lymphocytes were done as new techniques became available.

Studies were done using specific markers to distinguish B-cell types, i.e., identification of lymphocytes with membrane bound immunoglobulins and the capacity to form rosettes with the erythrocyte-antibody-complement complex (EAC-RFC), and T-

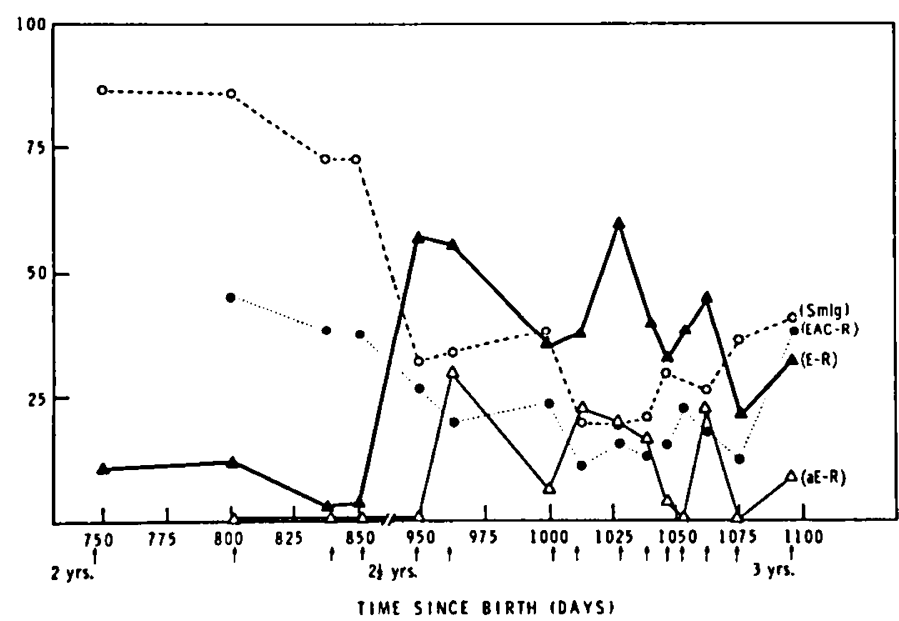

Fig. 1. Changes in percentages of T-and B-cell types in the peripheral blood lymphocytes of severe combined immune deficiency patient between the ages of 24 and 36 months (39). Smlg; surface membrane immunoglobulins; EAC-R: erythrocyte, antibody, complement-rosetteforming cells; E-R: erythrocyte-rosette-forming cells. aE-R: active erythrocyte rosettes. Arrows denote ages when studies were done. cell types, i.e., cells showing capacity to spontaneously form rosettes with sheep erythrocytes. At 2 months (64) a study of peripheral blood lymphocytes bearing membrane-bound immunoglobulins showed $36 \%$ with $\mathrm{IgM}, 40 \%$ with $\mathrm{IgG}$, and $16 \%$ with $\operatorname{IgA}$. This was in contrast to control values of $10 \%$ for $\operatorname{IgM}$, $20 \%$ for $\mathrm{IgG}$, and $5 \%$ for $\operatorname{lgA}$. Seven studies, from two different laboratories $(14,63)$, done at intervals during the first and second years of life, indicated that SmIg-bearing cells ranged from $55-100 \%$ of the total lymphocytes (average was $80 \%$ ). Peripheral blood counts during the first 2 years showed that the average white cell count was $5.3 \times 10^{3}$ with an average of $35 \%$ lymphocytes. When the patient was 2 years old further studies were done (40). The percentage of cells bearing surface immunoglobulins was still high (72-86\%) in comparison with control subjects $(20-26 \%)$ and $58-80 \%$ of these lymphocytes bore surface IgM. Twenty-seven to $47 \%$ were EAC-RFC; by comparison $20-27 \%$ of lymphocytes from control subjects were EAC-RFC. The cells with the T-cell marker of E-rosette formation were low (3-12\%) in comparison with control values (53$71 \%)$. Incubation with calf thymosin failed to increase the number of lymphocytes showing T-cell characteristics in vitro (40).

Between the ages of 2.5 and 4 years striking changes (Fig. 1) were observed (39). Although there were marked fluctuations in the percentages of $\mathrm{B}$ - and T-cell types, at specific times the percentage of $\mathrm{B}$-cell types decreased whereas that of T-cell types significantly increased. By 3 years of age $20-40 \%$ of the lymphocytes bore SmIg and 10.5-39\% bore EAC-RFC receptors. At the same time E-RFC increased to $19-60 \%$. This represents a dramatic shift approaching a normal distribution. Whether or not this represents a permanent change is not known since this is the first SCID child in whom such fluctuations have been demonstrated. These findings have been demonstrated independently in four laboratories (63).

\section{ELECTRON MICROSCOPY}

Studies of the lymphocytes between 3 and 10 months of age (13) showed that they were atypical. There was an increased ratio of cytoplasmic to nuclear area but the cytoplasm appeared empty with abundant smooth but no rough endoplasmic reticulum. The nucleus showed no aggregated ribosomes or nuclear pores. The nuclear membrane appeared to pull away from the nuclear space. Scanning electron microscopy revealed a great majority of cells with many villous projections. At 15 months of age a second population of smaller lymphocytes was present. This change was detected 4 months after the administration of the first dose of TF. The new cell type showed more characteristics of normal lymphocytes; i.e., higher density cytoplasm, detectable amounts of rough endoplasmic reticulum, and a more intact nuclear membrane. Approximately $10 \%$ of the peripheral blood lymphocytes were of the new type. These new cells increased in number until, at 4 years of age, they represented $93 \%$ of the lymphocytes present (Fig. 2).

\section{NONSPECIFIC LYMPHOCYTE FUNCTIONS}

In previous studies it has been demonstrated that lymphocytes from normal donors, activated via $\mathrm{C} 3$ membrane receptors, were able to nonspecifically destroy target cells and to produce lymphotoxin (41). The expression of these $C 3$ receptor-induced effector responses did not appear to be dependent on the presence of humoral immunocompetency. Lymphocytes bearing C3 receptors (CRL) from patients with congenital agammaglobulinemia or selective IgA deficiency, B-cell deficiencies showed cytotoxicity and produced lymphotoxin at levels comparable to CRL from normal individuals (31). Similar studies on the present SCID patient at 2.5 years of age are described below.

The nonspecific cytotoxicity of lymphoid subpopulations from the patient was compared with that of cells from normal donors 

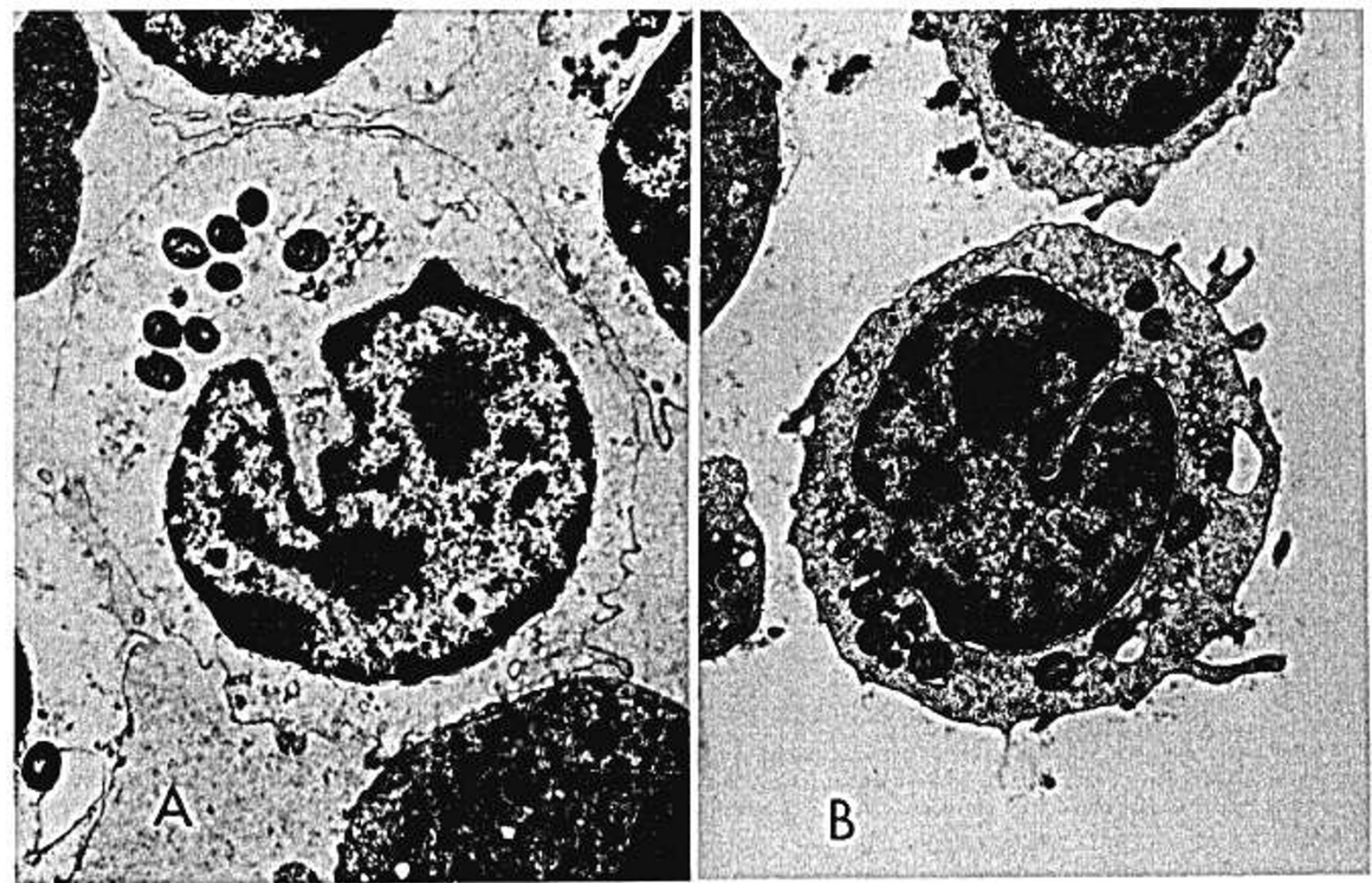

Fig. 2. Changes in ultrastructural characteristics of lymphocytes of the severe combined immune deficiency patient. $A$ : demonstrates the only lymphocyte type observed in studies done between 3 and 10 months of age $(\times 6,200) . B$ : more normal lymphocyte type first observed at 15 months and now constituting $93 \%$ of the lymphocytes present $(\times 6,280)$. Reprinted from Criswell et al. $(13)$ by permission of Experimental Hematology.

Table 7. Cytotoxicity of lymphoid subpopulations from normal donors and a severe combined immune deficiency (SCID) patient at 30 months ${ }^{1}$

\begin{tabular}{|c|c|c|c|c|c|}
\hline \multirow{2}{*}{$\begin{array}{l}\text { Lymphoid subpopulations } \\
\text { E-RFC }\end{array}$} & \multirow{2}{*}{$\begin{array}{c}\text { Target cell lympho- } \\
\text { cyte ratio }\end{array}$} & \multicolumn{2}{|c|}{ Normal donors $(n)$ mean $\% \pm \mathrm{SE}^{2}$} & \multicolumn{2}{|c|}{$\begin{array}{c}\text { SCID patient }(D V)(n) \text { mean \% } \\
\pm \mathrm{SE}^{2}\end{array}$} \\
\hline & & (9) & $1.2 \pm 0.3$ & (2) & $1.2 \pm 1.05$ \\
\hline Non-E-RFC & $1: 20$ & (4) & $1.5 \pm 0.6$ & (1) & 2.1 \\
\hline Non-E-RFC + E & $1: 20$ & (3) & $3.4 \pm 0.4$ & (1) & 1.8 \\
\hline Non-E-RFC + EA & $1: 20$ & (3) & $3.8 \pm 0.5$ & (1) & 0.7 \\
\hline Non-E-RFC + autologous sera & $1: 20$ & (4) & $1.5 \pm 0.6$ & (1) & $\mathrm{ND}^{3}$ \\
\hline EAC (alone) & $10^{4}$ & (3) & $3.1 \pm 0.02$ & (3) & $3.1 \pm 0.6$ \\
\hline \multirow[t]{2}{*}{ EAC-RFC } & $1: 20$ & (8) & $17.5 \pm 2.1$ & (8) & $3.7 \pm 0.6$ \\
\hline & $1: 10$ & (7) & $16.3 \pm 1.5$ & (7) & $4.1 \pm 0.6$ \\
\hline
\end{tabular}

\footnotetext{
${ }^{1} n$ : number of experiments (for normal donors each experiment represents a separate donor); E-RFC: lymphocytes capable of forming rosettes with sheep erythrocytes; EA: erythrocyte-antibody complex; EAC: erythrocyte-antibody-complement complex; EAC-RFC: lymphocytes capable of forming rosettes with the erythrocyte-antibody-complement complex.

${ }^{2}$ Mean percentage of ${ }^{31} \mathrm{Cr}$ release $\pm \mathrm{SE}$ utilizing human melanoma target cells $(\mathrm{Sh}-1)$; total ${ }^{\text {s1 }} \mathrm{Cr}$ incorporation $(9,558 \pm 353 \mathrm{cpm})$ and spontaneous ${ }^{31} \mathrm{Cr}$ release $(281 \pm 26 \mathrm{cpm})$; percentage of cytotoxicity $=$ experimental ${ }^{31} \mathrm{Cr}$ release minus spontaneous ${ }^{31} \mathrm{Cr}$ release, divided by total ${ }^{31} \mathrm{Cr}$ incorporated minus spontaneous ${ }^{\mathrm{B1}} \mathrm{Cr}$ release $\times 100$.

${ }^{3}$ Not done.
}

(Table 7). The T cells (E-RFC) and non-E-RFC (enriched B cells) from the patient and normal individuals gave negligible direct cytolytic responses. In normal donors, $\mathrm{C} 3$ receptor-activated $B$ cells (activated EAC-RFC) gave cytotoxic responses independent of antibody or EAC constituents. The activated EAC-RFC from the SCID patient failed to express cytoxicity $(4.1 \pm 0.6)$ significantly greater than was obtained with non $E$ RFC incubated with either individual EAC constituents $(3.8 \pm$ $0.5)$, autologous sera $(1.5 \pm 0.6)$, or EAC alone $(3.1 \pm 0.02)$.

Lymphotoxin (LT) and leukocyte migration inhibition factor, lymphokines produced by EAC-activated CRL from normal do- nors and the SCID patient, are presented in Table 8. Culture supernatants from normal EAC-RFC contained 7-8 times more LT than unstimulated E-RFC and 2-3 times more LT than PHA-stimulated E-RFC. The EAC-RFC from the SCID patient consistently produced LT levels 3-4 times those of the E-RFC from either the patient or the normal donors. These preliminary findings suggested that EAC-rosetting of CRL from the SCID patient had induced LT-like activities.

The same supernatant fluids were assayed for the ability to inhibit the migration of normal donor leukocytes (Table 8). Studies with normal donors indicated that EAC-RFC superna- 
Table 8. Soluble mediator production by complement receptoractivated lymphocytes (CRL) from normal donors and a severe combined immune deficiency (SCID) patient at 30 months $^{1}$

\begin{tabular}{|c|c|c|c|c|c|}
\hline \multirow{2}{*}{$\begin{array}{c}\text { Lymphoid subpop- } \\
\text { ulations }\end{array}$} & \multirow{2}{*}{$\begin{array}{c}\text { Super- } \\
\text { natant } \\
\text { dilution }\end{array}$} & \multicolumn{2}{|c|}{ Normal donors } & \multicolumn{2}{|c|}{ SCID patient $(D V$} \\
\hline & & (n) & Mean $\% \pm \mathrm{SE}$ & $(n)$ & Mean $\% \pm \mathrm{SE}$ \\
\hline \multicolumn{6}{|l|}{ Lymphotoxin } \\
\hline \multirow[t]{2}{*}{ E-RFC } & $1: 3$ & (7) & $1.3 \pm 0.2^{2}$ & (5) & $1.1 \pm 0.1$ \\
\hline & $1: 6$ & (10) & $1.2 \pm 0.1$ & & $\mathrm{ND}^{3}$ \\
\hline \multirow{2}{*}{$\begin{array}{c}\text { E-RFC + PHA } \\
(1 \mu \mathrm{g} / \mathrm{ml})\end{array}$} & $1: 3$ & (3) & $2.6 \pm 0.2$ & & ND \\
\hline & $1: 6$ & (6) & $4.4 \pm 0.9$ & & ND \\
\hline \multirow[t]{2}{*}{ EAC-RFC } & $1: 3$ & (6) & $8.6 \pm 0.6$ & (5) & $4.0 \pm 0.2$ \\
\hline & $1: 6$ & (12) & $7.5 \pm 0.3$ & (3) & $3.7 \pm 0.1$ \\
\hline Leukocyte migration & $1: 2$ & (5) & $60 \pm 7$ & (5) & $40 \pm 16$ \\
\hline $\begin{array}{l}\text { inhibition factor } \\
\text { (EAC-RFC) }\end{array}$ & $1: 3$ & (3) & $38 \pm 3$ & (3) & $10 \pm 3$ \\
\hline
\end{tabular}

${ }^{1} n$ : Number of experiments (for normal donors each experiment represents a separate donor); E-RFC: lymphocytes capable of forming rosettes with sheep erythrocytes; PHA: phytohemagglutinin; EACRFC: lymphocytes capable of forming rosettes with the erythrocyteantibody-complement complex.

${ }^{2}$ Mean percentage of ${ }^{51} \mathrm{Cr}$ release \pm SE (see legend of Table 7).

${ }^{3}$ Not done.

4 Mean percentage of migration inhibition $\pm S E$.

tant fluids contained appreciable MIF activity $(60 \pm 7 \%)$. Consistent with the positive LT responses, C3 receptor-stimulated cells also produced MIF activity $(40 \pm 16 \%)$ greater than the background (15\%) level.

No correlation was evident between fluctuations in absolute numbers of $\mathrm{C} 3$ receptor-bearing cells in peripheral blood and the presence of LT and MIF responses.

\section{DISCUSSION AND CONCLUSION}

$D V$ has shown little ability to respond immunologically, both T-cell and B-cell functions being severely defective. Except for the low levels of $\mathrm{Clq}$, no abnormalities have been found in other functions related to host defenses. Extensive studies of such functions, however, have not been done.

The ability of this patient to respond immunologically was not completely absent even during the first year of life when evidence of immune responsiveness was shown by the minimal skin response to $\mathrm{KLH}$ after multiple antigen injections, by the occasional, very low responses to mitogens in lymphocyte culture, and by the effects of in vivo and in vitro responses after injection of TF. The fact that the patient has been able to tolerate limited bacterial contamination could indicate the presence of some specific immune responsiveness, but it is more likely that his protection from invasion and infection by bacteria has been due to phagocytic activity and other nonspecific host defenses.

The change, beginning at $\mathbf{1 4 . 5}$ months, in ultrastructural physical characteristics of lymphocytes toward a normal appearance is interesting in view of the appearance of the new cell type within 4 months after the first injection of TF. It is impossible to say that the TF injections triggered development of the new cell type, although it is tempting to speculate that this might have been the case. No immediate changes in other measurements were detected to indicate that the newly developed cell type was expressing more normal lymphocyte activity. Specifically, the changes in percentages of lymphocyte types denoted by surface markers were not observed until a year later, so that the internal cell changes could not be attributed to the change from a predominance of B- to T-cell surface marked cells. The TF administration was the only externally imposed event that could be temporally related to a permanent change in the immune system. It has been speculated that antigen stimulation via bacterial contamination could possibly have elicited responses that led to changes in the immune system, but no changes could be temporally related to the acquisition of new organisms.
Although fluctuations were always present in the percentages of lymphocytes with B-cell and T-cell markers, the marked shift toward normal occurred after the patient was 2 years old (39). Such changes, in themselves, would not necessarily indicate an increase in functional capacity of the lymphocytes, but the subsequent detection of $7 \mathrm{~s}$ and $19 \mathrm{~s}$ serum immurioglobulins and loss of the abnormal $4 \mathrm{~s}$ component would suggest that the patient has developed an ability to produce normal immunoglobulins. The detection of very low levels of serum $\operatorname{IgA}$ for the first time at 39 months may also be indicative of developing ability to produce immunoglobulins, but it is not yet known whether this is a normal serum fraction of $\operatorname{IgA}$ or a paraprotein similar to that reacting with anti-IgM in the early immunodiffusion assays.

Studies at 2.5 years showed that activation of lymphocytes with complement receptors induced low, but significant LT and MIF levels and negligible levels of CRL-mediated cytotoxicity. The low CRL cytotoxicity levels may have indicated some reactivity but evaluation was obscured by technical limitations which gave background levels $(3.8 \pm 0.5)$, almost equal to the high experimental value $(5.6 \%)$. The expression of $\mathrm{LT}$ and MIF activities indicated that this patient was capable of nonspecific host defense responses. The low, but fluctuating CRL responses may reflect the responses of small transient subpopulations of cells. Further indication of this possibility can be drawn from the transient responses to PHA. These findings, along with the transient responses after transfer factor injections, would suggest an impairment of the ability of this SCID patient to expand or sustain functional subpopulations that are essential to immunologic responsiveness.

Several explanations for the changes which have occurred in this patient's lymphocytes may be considered, e.g., that they represent immunologic reactivity which was always present but unstimulated, that they are manifestations of a slow maturation of the immune system, or that they are changes which have taken place despite an intrinsic defect in the immune system:

The possibility that the changes are indications of normal immunologic reactivity which was always present but unstimulated may be rejected for a number of reasons. The patient has encountered many antigens from which he could have received stimulation, for instance in utero from placental crossover of maternal antigens such as immunoglobulins and probably also of maternal lymphoid cells, and after birth from his food, from his early encounter with $\boldsymbol{A}$. faecalis, from injections of various antigens during the early months of life, and from the gradual acquisition of a mucocutaneous bacterial flora. In germ-free animal models, morphologic and functional development of the immune apparatus follows adequate stimulation within a few days. Such immunologic development is certainly not compatible with the slow and even now incomplete change toward normal in this patient.

Evidence which indicates that the changes do not represent a natural, well ordered although slow maturation of the immune system includes the following. (1) The early characteristics of the patient's lymphocytes in electron microscopic studies did not resemble any recognized stage of normal maturation. (2) The high proportion of cells bearing surface immunoglobulins is not typical of any known stage of normal maturation. (3) The transfer factor studies showed some effect on in vivo and in vitro responses even in the absence of detectable $\mathrm{T}$ cells. This type of effect is not known or even postulated to occur during developmental sequence. (4) There is no evidence that the evolution of the immunoglobulin system passes through a stage characterized by production of a paraprotein similar to the $4 \mathrm{~s}$ component found in $D V$. Thus, it seems likely that this child's defect is not one of simple maturational delay.

The most reasonable explanation for the changes seems to be that an intrinsic defect of the immune apparatus resulted in an uneven development of the various aspects involved in the maturation of the immunocytes. Thus, some parts of the developmental sequence did occur (B surface markers developed) whereas others developed aberrantly or not at all (the internal 
lymphocyte structure looked entirely abnormal). This uneven development resulted at birth in absence or undetectable numbers of normally functioning cells of both $\mathrm{B}$ and $\mathrm{T}$ lines. Other children with SCID, at this point, would have been subjected to intense antigenic assault. Such assault could result in further damage to a lymphocyte population which was already functioning inadequately or perhaps not at all. In cases where the child is protected from such antigenic assault, it seems possible that

Copyright $\odot 1977$ International Pediatric Research Foundation, Inc. further opportunity for development may be provided, through increased survival time as well as through protection against overwhelming antigenic exposure. In the present case it appears that further development has already taken place; whether or not this will proceed to the emergence of an adequately functioning immune apparatus remains a question to be answered only by continued observation.

Pediat. Res. 11: 78-79 (1977)

\title{
V. Hematology
}

\author{
DONALD J. FERNBACH, KENNETH A. STARLING, AND JOHN M. FALLETTA
}

Department of Pediatrics, Baylor College of Medicine and the Research Hematology Laboratory, Texas Children's Hospital, Houston, Texas, USA

The hematologic surveillance of this patient revealed no dramatic differences from other children with SCID not maintained in a gnotobiotic environment. However, the absence of significant complicating infections - in fact, the absence of complications of any type-enabled this staff to accumulate data that probably reflect changes attributable to the natural history of this disorder more accurately than those that could be obtained under any other circumstnaces.

Details of the function of the neutrophils (Rebuck skin window studies and phagocytic studies) have been included in the section on immunology. No studies on the motility or phagocytic activity of the monocytes were done. The peripheral counts enumerated here were all obtained by conventional methods. Some of the early blood counts were done on blood obtained by heel puncture, but the majority were performed on venous blood samples.

\section{HEMOGLOBULIN, HEMATOCRIT, RED BLOOD CELL COUNT}

The lowest recorded hemoglobulin was $10.0 \mathrm{~g} / 100 \mathrm{ml}$, and the lowest hematocrit was $29.3 \%$ on the same day at approximately 3 months of age. During the first 3 months of life, the red cell count ranged from $3.51 \times 10^{6} / \mathrm{mm}^{3}$ to $4.44 \times 10^{6} / \mathrm{mm}^{3}$. All red cell counts thereafter have ranged from $4.0-5.0 \times 10^{8} / \mathrm{mm}^{3}$.

In consideration of the presumed role of enteric bacteria in absorption or metabolism of vitamin $\mathrm{B}_{12}(12)$, parenteral vitamin $\mathrm{B}_{12}, 500 \mu \mathrm{g}$, was administered monthly until May 1973, at which time the patient was 18 months of age. Parenteral folic acid, 5 $\mathrm{mg}$, was also administered monthly until the same date. Up to that time, six bacterial organisms had penetrated the environment to colonize the child as shown in the section on gnotobiotic care. Only four of these persisted, although four other microbial organsims were later found to have colonized the child, so that by March 1974, there were eight persisting organisms. Except for the expected macrocytosis in the newborn period, there has been no alteration in the size of the peripheral red blood cells nor any other specific evidence of vitamin $B_{12}$ deficiency through August 1975.
It is appropriate to note at this point, relative to the role of bacterial organisms, that although no prothrombin times were recorded, only a few small ecchymoses were noted between 2 and 3 months of age. Vitamin $\mathrm{K}$ was administered parenterally until the spring of 1972 and orally until May 1973. No other bleeding manifestations have been documented and there is no reason to believe that there was significant hypoprothrombinemia at any time.

\section{LEUKOCYTES}

The absolute leukocyte levels are charted in Figure 1. The neutrophils, lymphocytes, and monocytes are similarly charted in Figure 2. Since September 1972 (age 1 year) the absolute leukocyte count has remained above $4.0 \times 10^{3} / \mathrm{mm}^{3}$. The last absolute lymphocyte count in excess of $2.0 \times 10^{3} / \mathrm{mm}^{3}$ was recorded on October 10,1972 when the child was 13 months of age. The absolute monocyte count gradually rose, with fluctuations, from 2.5 years of age to an apparently stable level at the present time. On a number of occasions the absolute monocyte count exceeded the absolute lymphocyte count. The total mononuclear cell count (monocytes plus lymphocytes) remained approximately 2,000 until September, 1974 when the patient was 3 years old. Since then, the combination of these counts has remained below $1,500 / \mathrm{mm}^{3}$. The bizarre appearance of the "monocyte" on the Rebuck skin window preparations (see Section IV) raises a question as to the exact nature of this cell which has a lymphocyte-like nucleus surrounded by an abundant polychromatophilic cytoplasm. In our experience, these are unlike mononuclear cells seen on other skin window preparations.

The single severe neutropenic episode during the second month of age occurred during gentamicin therapy which was administered in an attempt to eradicate the $S$. epidermidis. Within 3 days the count had risen to an adequate level although no changes were made in therapy and there was no apparent evidence of clinical infection at that time.

Eosinophil and basophil levels were unremarkable. During the first 3 months the eosinophils fluctuated up to an absolute count of $1,080 / \mathrm{mm}^{3}$ but since that time the level has ranged 